\title{
The role of a nested polymerase chain reaction in the diagnosis of Pneumocystis carinii pneumonia
}

\author{
R Evans, A W L Joss, D Parratt, T H Pennington, D O Ho-Yen
}

\begin{abstract}
Aim-To compare the techniques and results of a nested PCR and an immunofluorescence assay (IFA) for the detection of Pneumocystis carinii infection; to consider the role of the nested PCR in the diagnosis of $P$ carinii pneumonia (PCP).

Methods-Serial dilutions of two known $P$ carinii positive samples were tested by IFA and PCR to determine their relative sensitivities. Seventy eight respiratory samples (15 from 11 patients with HIV infection/ acquired immunodeficiency syndrome (AIDS) and 63 from 42 patients with other forms of immunodeficiency) were tested using both assays, and the costs and technical requirements of each assay were assessed.
\end{abstract}

Results-The PCR had a greater relative sensitivity over the IFA of $2 \times 10^{1}$ to $2 \times 10^{3}$ fold in a postmortem lung sample and $2 \times 10^{5}$ to $2 \times 10^{6}$ fold in a bronchoalveolar lavage sample from a patient with PCP. $P$ carinii was detected in all 15 samples from the patients with HIVIAIDS by both IFA and PCR. Of the 63 samples from the patients with immunodeficiencies other than HIVIAIDS, the PCR was more sensitive than IFA.

Conclusions-The nested PCR is a more sensitive assay than the IFA. It may be useful in the diagnosis of PCP in patients with immunodeficiencies other than HIVI AIDS. Similarly, PCR may be of benefit for this patient group as less invasive specimens are needed. PCR has an increasing role to play in the diagnosis of PCP in the routine laboratory.

(f Clin Pathol: Mol Pathol 1995;48:M347-M350)

Keywords: Pneumocystis carinii, PCR, immunofluorescence assay, acquired immunodeficiency syndrome.

Medical Microbiology, Ninewells Hospital and Medical School, Dundee

D Parrat

Medical Microbiology, Aberdeen University Medical School, Foresterhill, Aberdeen $\mathrm{T} \mathrm{H}$ Pennington

Correspondence to: Dr Roger Evans,

Microbiology Department, Microbiology Departmen Raigmore Hospital NHS Trust, Inverness IV2 3UJ Accepted for publication 31 August 1995
Sensitivity and specificity of the IFA is good with bronchoalveolar lavage (BAL) samples but can be reduced in less invasive specimens such as induced sputa. $^{2}$ More recently, the development of the polymerase chain reaction
(PCR) as a diagnostic tool has introduced a very sensitive and specific test for the diagnosis of PCP. ${ }^{23}$ It can potentially be used with less invasive specimens where the organism burden is below the detection level of other routine tests such as the IFA. ${ }^{34}$

Various DNA amplification methods have been published which detect $P$ carinii, but the nested PCR has a number of distinct advantages over those which require probing of the DNA product by Southern blot hybridisation. The assay time is shorter, less technical training is required and the cost of the test is lower. ${ }^{3}$ Nevertheless, some pathologists consider that the PCR is an expensive and technically complicated assay when compared with the IFA currently in routine use and thus PCR is reserved only for specialised laboratories. This paper attempts to identify the role of the PCR in the diagnosis of PCP.

\section{Methods}

Seventy eight respiratory samples from 53 patients with HIV infection $(n=11)$ or another form of immunodeficiency $(n=42)$ were tested. These included 42 BAL samples, six bronchial washings, 24 induced sputum samples, four tracheal aspirate samples, and two postmortem lung tissue samples. Of the samples previously tested using the IFA, 29 were tested retrospectively using PCR and 49 prospectively using both IFA and PCR. The retrospective samples had been stored at $-20^{\circ} \mathrm{C}$. Eighteen of the prospective samples were initially tested using the IFA at the Medical Microbiology Department at Ninewells Hospital, Dundee, and were then sent to the Microbiology Department, Raigmore Hospital, Inverness, for testing using the nested PCR. Results were exchanged after all testing was completed.

IMMUNOFLUORESCENCE ASSAY

Samples were mixed (v/v) with mucolysin (Prolab diagnostics) for 20 to 30 minutes at room temperature to solubilise mucus and were then washed twice in sterile distilled water at $3000 \mathrm{rpm}$ for 15 minutes. The IFA (Shield Diagnostics) was carried out according to the manufacturer's instructions apart from the pretreatment method, where trypsin $(0 \cdot 25 \%)$ was used instead of pronase. After acetone fixation on slides and incubation with anti-cyst monoclonal antibody, $P$ carinii cysts were detected using a fluorescein isothiocyanate conjugated 
Table 1 Results of PCR and IFA on 15 respiratory samples from patients with HIVIAIDS

\begin{tabular}{llllllll}
\hline & \multicolumn{1}{l}{ IFA } & & & \multicolumn{2}{l}{$P C R$} \\
\cline { 2 - 4 } Sample type & Positive & Equivocal & Negative & & Positive & Negative \\
\hline BAL $(\mathrm{n}=7)$ & 5 & 0 & 2 & & 5 & 2 \\
Induced sputum $(\mathrm{n}=8)$ & 3 & 0 & 5 & & 3 & 5 \\
Total $(\mathrm{n}=15)$ & 8 & 0 & 7 & & 8 & 7 \\
\hline
\end{tabular}

antibody directed against the bound monoclonal antibody. According to kit criteria, a positive result was indicated by $>5$ cysts per $20 \mu$ sample; $1-5$ cysts indicates an equivocal result. The cost per assay was calculated, and the time and expertise required for the assay were noted.

\section{POLYMERASE CHAIN REACTION}

PCR was carried out on $20 \mu \mathrm{l}$ samples, both neat and diluted 1 in 10 in sterile distilled water. The samples were treated with mucolysin and digested using proteinase $\mathrm{K}$ (one hour, $55^{\circ} \mathrm{C}$, final concentration $200 \mu \mathrm{g} / \mathrm{ml}$ ). The nested PCR used primers representative of part of the gene coding for the large sub unit of mitochondrial RNA. ${ }^{4}$ The protocol has been described previously, ${ }^{3}$ but was modified to omit the extension period of $72^{\circ} \mathrm{C}$ for one minute for each thermal cycle of the nested run, shortening the run by 20 minutes. This was possible because the 125 base pair target is short enough to be synthesised in the time taken by the thermal block to heat from $70^{\circ} \mathrm{C}$ to $75^{\circ} \mathrm{C} .^{5}$ The target band was identified by transillumination of ethidium bromide stained DNA with ultraviolet light after agarose gel electrophoresis. Both samples were tested in duplicate by PCR. The cost per assay was estimated, and the time and expertise required for the assay were noted.

\section{SENSITIVITY EXPERIMENTS}

Two $P$ carinii positive samples were serially diluted and the diluted samples tested by both IFA and PCR. One of the samples was a cyst rich suspension of $P$ carinii derived postmortem from the lung of a patient with PCP; the other was a BAL sample from a patient with PCP who had responded to specific anti-pneumocystis therapy. For the IFA, samples were tested at the following serial dilutions: $1 \times 10^{-1}, 2 \times 10^{-2}$, $1 \times 10^{2}, \quad 5 \times 10^{-3}, \quad 2 \times 10^{-3}, \quad 1.3 \times 10^{-3}$, $1 \times 10^{-3}$, and $5 \times 10^{-4}$. The PCR samples were diluted 10-fold from the same original sample. As the PCR samples are diluted 1 in 2 in the proteinase $\mathrm{K}$ solution, the final dilutions ranged from $5 \times 10^{-2}$ to $5 \times 10^{-11}$ in decreasing 10 fold dilutions.

Table 2 Results of PCR and IFA on 63 respiratory samples from patients with immunodeficiencies other than HIVIAIDS

\begin{tabular}{lllllll}
\hline & \multicolumn{3}{l}{$I F A$} & & & \multicolumn{2}{l}{$P C R$} \\
\cline { 2 - 4 } Sample type & Positive & Equivocal & Negative & & Positive & Negative \\
\hline BAL $(\mathrm{n}=35)$ & 4 & 4 & 27 & & 10 & 25 \\
Bronchial washings $(\mathrm{n}=6)$ & 1 & 1 & 4 & & 3 & 3 \\
Induced sputum $(\mathrm{n}=16)$ & 0 & 1 & 15 & & 2 & 14 \\
Tracheal aspirate $(\mathrm{n}=4)$ & 1 & 0 & 3 & & 2 & 2 \\
Lung tissue $(\mathrm{n}=2)$ & 0 & 0 & 2 & & 0 & 2 \\
Total $(\mathrm{n}=63)$ & 6 & 6 & 51 & & 17 & 46 \\
\hline
\end{tabular}

\section{Results}

Cysts were detected to a dilution of $1 \times 10^{-3}$ of the postmortem lung tissue sample and to $1 \times 10^{-2}$ of the BAL sample by the IFA. The PCR amplified detectable $P$ carinii DNA at dilutions of $5 \times 10^{-5 / 5} \times 10^{-7}$ and $5 \times 10^{-8 /}$ $5 \times 10^{-9}$ of these respective samples. Thus, the PCR has a greater sensitivity of $2 \times 10^{1}$ to $2 \times 10^{3}$ fold in the postmortem lung sample and $2 \times 10^{5}$ to $2 \times 10^{6}$ fold in the BAL sample compared with the IFA.

In the 15 samples from the 11 patients with HIV/AIDS there was no difference in the results obtained with the IFA and PCR with either the invasive BAL samples or the less invasive induced sputum samples (table 1 ). The results of the IFA and PCR on the remaining 63 samples from 42 patients with other forms of immunodeficiency-for example, transplant recipients and those with haematological and non-haematological malignancies, are shown in table 2 . Six of the 63 samples tested by IFA had greater than five fluorescing cysts $/ 20 \mu \mathrm{l}$, six had equivocal results and the remainder (51) were negative. The PCR produced positive results in 17 samples, significantly more than with the IFA alone (McNemar test, $\mathrm{p}<0.001$ ) and the positive and equivocal IFA samples combined (McNemar test, $\mathrm{p}<0.03$ ). The increased sensitivity was apparent in all specimen types except lung. In four of the five cases where results on different specimen types could be compared, the less invasive specimen yielded the same result as the BAL specimen (table 3). In one case (patient 2) the BAL sample was positive one day before the tracheal aspirate, and in both of these samples only the PCR was positive. For patient 4 , the PCR remained positive longer than the IFA following successful treatment.

The relative costs of PCR and the IFA were assessed in terms of labour, accommodation, consumables, and capital equipment. The overall assay time for PCR (eight hours) is longer but the operator time is shorter (two hours) than for the IFA (three to four hours). PCR time is also more predictable, with less frequent

Table 3 Results from five patients with immunodeficiencies other than HIVIAIDS investigated by sample type

\begin{tabular}{|c|c|c|c|c|}
\hline $\begin{array}{l}\text { Patient } \\
\text { no. }\end{array}$ & Sample type & $\begin{array}{l}\text { Days after first } \\
\text { specimen taken }\end{array}$ & $P C R$ & $I F A$ \\
\hline 1 & $\begin{array}{l}\text { BAL } \\
\text { BAL } \\
\text { BAL } \\
\text { Tracheal aspirate }\end{array}$ & $\begin{array}{r}0 \\
8 \\
22 \\
22\end{array}$ & $\stackrel{\oplus}{\oplus}$ & $\stackrel{\oplus}{\oplus}$ \\
\hline 2 & $\begin{array}{l}\text { BAL } \\
\text { Tracheal aspirate } \\
\text { Tracheal aspirate }\end{array}$ & $\begin{array}{l}0 \\
0 \\
1\end{array}$ & $\stackrel{\oplus}{\oplus}$ & $\stackrel{\ominus}{\ominus}$ \\
\hline 3 & $\begin{array}{l}\text { BAL } \\
\text { Induced sputum }\end{array}$ & $\begin{array}{l}0 \\
0\end{array}$ & $\stackrel{\ominus}{\ominus}$ & $\stackrel{\ominus}{\ominus}$ \\
\hline 4 & $\begin{array}{l}\text { BAL } \\
\text { Tracheal aspirate } \\
\text { BAL } \\
\text { BAL } \\
\text { BAL }\end{array}$ & $\begin{array}{r}0 \\
0 \\
15 \\
21 \\
25\end{array}$ & $\begin{array}{c}\stackrel{\oplus}{\oplus} \\
\oplus \\
\oplus \\
\oplus\end{array}$ & $\frac{\stackrel{\oplus}{\oplus}}{\stackrel{+T}{\ominus}=}$ \\
\hline 5 & $\begin{array}{l}\text { BAL } \\
\text { Induced sputum }\end{array}$ & $\begin{array}{l}0 \\
0\end{array}$ & $\stackrel{\oplus}{\oplus}$ & $+T$ \\
\hline
\end{tabular}

$\oplus=$ Positive

$\ominus=$ Negative 
requirement for repeat testing and a lower fractional time increment per additional test sample. The overall skill requirements for the tests are similar; PCR demands more stringent precautions against cross contamination but these can be met by the judicious use of existing accommodation. The cost per separate PCR assay for consumables, including Taq polymerase, buffer, primers, dNTPs, DNA marker ladder, photographic film, and plastics is approximately $£ 15$, which doubles when 10 samples are tested simultaneously. This compares with about $£ 20$ per IFA test regardless of whether the 10 assays in the kit are used separately or simultaneously. PCR capital costs are also lower, $£ 4500-5000$ (before VAT) for thermal cycler, transilluminator and electrophoresis apparatus compared with $£ 10000$ 12000 for a fluorescence microscope.

\section{Discussion}

The results of dilution experiments confirm that the PCR is more sensitive than the IFA for the detection of $P$ carinii organisms in respiratory samples. The $2 \times 10^{1}$ to $2 \times 10^{3}$ increase in the sensitivity of the PCR with the postmortem lung sample is likely to be because of the inherent sensitivity of the technique and its ability to detect individual organisms; a single cyst can contain up to eight organisms. The relative sensitivity of the PCR with the BAL sample was greater by $2 \times 10^{5}$ to $2 \times 10^{6}$ fold. The increase in sensitivity may also be because of the detection of the trophozoite form of the organism which is considered to be at least 100 times more numerous than cysts in a BAL sample. ${ }^{6}$ The cyst density (and perhaps the trophozoite population) in BAL and induced sputum samples can vary in HIV/ AIDS patients with PCP and there is also a correlation between patient survival and the predominant stage of the organism. ${ }^{7}$ Therefore, because PCR can be used to detect both the cyst and trophozoite forms of $P$ carinii, it may be of more use in the diagnostic laboratory.

The patients with HIV/AIDS were analysed separately from those with other immunodeficiencies as they tend to have had symptoms longer ${ }^{8}$ and have a greater organism load in their BAL and induced sputum samples than patients with other immunodeficiencies. ${ }^{9}$ In the patients with HIV/AIDS the IFA was as sensitive as PCR, whereas in those with other immunodeficiencies PCR was significantly more sensitive than the IFA $(p<0.001)$. At present, as invasive procedures are required for specimen collection, most clinicians avoid taking sequential specimens if possible, unless there is difficulty in making a diagnosis. In the present study sequential specimens from around the time of infection were available from 10 of 53 patients. In seven the results on PCR and IFA were in agreement, but in the remaining three the PCR results were positive and the IFA negative. In one patient an initial induced sputum sample was positive on PCR only, but a second sample taken a day later was also positive on IFA. In another patient (patient
2, table 3) a BAL sample was PCR positive followed by a tracheal sample a day later; however, the IFA was negative in both samples. In both of these patients PCR therefore enabled a diagnosis to be made and treatment to be instigated earlier. Specimens from a third patient (patient 4, table 3) demonstrate how the IFA becomes negative earlier after treatment than PCR. PCR may still be useful in such a situation when retrospective confirmation of diagnosis is required in patients already receiving treatment.

Apart from equalling or improving upon the sensitivity and specificity of the IFA, PCR, to become a routine test, should also fulfil the following additional criteria: a short procedure time, within one working day or less, technical ease and the cost should not be prohibitive. Although the IFA has the advantage of being a shorter assay than the PCR when $>5$ cysts/ well are seen, in cases where the organism load may be low or multiple samples are tested the IFA may lose its time advantage as the PCR can test up to 11 samples per assay with relatively little addition to the overall time required for one sample. The interpretation of IFAs requires a trained and skilled operator for an accurate diagnosis to be made. In our experience the cyst form may be confused at times with other fungi which occasionally fluoresce despite the use of a specific monoclonal conjugate. In contrast, the nested PCR result is usually easy to read even for the untrained eye. The disadvantage of PCR is the possibility of contamination but if strict protocols are observed, the contamination risk is minimised. There is a perception that PCR is an expensive assay but our estimates indicate it is not necessarily more expensive in terms of labour and accommodation and is less expensive in terms of consumables and capital costs than IFA. The cost of setting up the PCR assay has also to be compared with the improved diagnosis it can provide: earlier diagnosis can mean quicker treatment and shorter hospital stays for patients, especially as many are in expensive intensive care beds; the use of less invasive samples; and the reduced need for repeat sampling for a diagnosis. Therefore, PCR is likely to be of cost benefit to the routine laboratory in the diagnosis of PCP.

These results indicate that for the majority of patients IFA continues to be one of the most sensitive methods for the rapid diagnosis of PCP. In patients with HIV/AIDS no differences were observed between IFA and PCR with both invasive (BAL) and less invasive (induced sputum) samples. In this group of patients the IFA is likely to remain the routine method of diagnosis although PCR has been shown to be useful in patients who present with-for example, granulomatous PCP when the routine methods may give false negative results. ${ }^{10}$ Nested PCR has a distinct advantage over IFA in patients with PCP, patients with a low organism burden, or a predominance of trophozoites and especially those with immunodeficiencies other than HIV/AIDS. Thus PCR is an important addition to the laboratory diagnosis of PCP and with greater 
use of the PCR technique, its role in the routine diagnosis of PCP is likely to become more predominant.

We are grateful for the help and cooperation of Drs K F Whyte and Dr H S Livingston. This work was supported by the Scottish Home and Health Department, grant no (K/MRS/50/C1828) Home and Health Department, grant no. (KMRS/5

1 Ho-Yen DO, Chatterton JMW, Joss AWL. Laboratory diag nosis of Pneumocystis carinii pneumonia. 7 Med Microbiol 1995;42:231-2.

2 Chatterton JMW, Ho-Yen DO. Laboratory investigation of Pneumocystis carinii pneumonia. Genitourin Med 1992; 68:336-41.

3 Evans R, Joss AWL, Pennington TH, Ho-Yen DO. The use of a nested polymerase chain reaction for detecting Pneumocystis carinii from lung and blood in rat and human infection. F Med Microbiol 1995;42:209-13.
4 Wakefield AE, Pixley FJ, Banerii S, Sinclair K, Miller RF, Moxon ER, et al. Detection of Pneumocystis carinii with DNA amplification. Lancet 1990;336:451-3.

5 Saiki RK, Gelfland DH. Introducing AmpliTaq DNA polymerase. Amplifications 1989;1:4-6.

6 Masur H, Jones TC. The interaction in vitro of Pneumocystis carinii with macrophages and L cells. $f$ Exp Med 1978;147:157-70.

7 Blumenfeld W, Miller CN, Chew KL, Mayall BH, Griffiss IM. Correlation of Pneumocystis carinii cyst density with mortality in patients with acquired immunodeficiency syndrome and pneumocystis pneumonia. Hum Pathol 1992; 23:612-18.

8 Kovacs JA, Hiemenz JW, Macher AM, Stover D, Murray HW, Shelhamer J, et al. Pneumocystis carinii pneumonia: A comparison between patients with the acquired immunodeficiency syndrome and patients with other immunodeficiencies. Ann Intern Med 1984;100:663-71.

9 Limper AH, Offord KP, Smith TF, Martin WJ. Differences in lung parasite number and inflammation in patients with and without AIDS. Am Rev Respir Dis 1989:140:1204-9.

10 Wakefield AE, Miller RF, Guiver LA, Hopkin JM. Granulomatous Pneumocystis carinii pneumonia: DNA amplification studies on bronchoscopic alveolar lavage samples. F Clin Pathol 1994;47:664-6. 